\title{
4NQO Carcinogenesis: A Model of Oral Squamous Cell Carcinoma
}

\author{
Carcinogenesis Inducida por 4NQO: Un Modelo de Carcinoma Oral de Células Escamosas \\ César Andrés Rivera Martínez
}

RIVERA, M. C. A. 4NQO carcinogenesis: a model of oral squamous cell carcinoma. Int. J. Morphol., 30(1):309-314, 2012.

SUMMARY: The experimental oral carcinogenesis induced by the chemical 4-nitroquinoline 1-oxide (4NQO) is one of the most frequent in the study of squamous cell carcinoma of the oral cavity (CCEC). The clear advantage is that the model is very similar to the physiological process of malignancy. The model has clear benefits by and is suitable for applications in therapeutic research.

KEY WORDS: 4NQO; Experimental carcinogenesis; Oral squamous cell carcinoma; Tongue.

\section{INTRODUCTION}

Oral cancer, most commonly in tongue, is a major cause of cancer deaths worldwide (Parkin et al., 2001). Oral squamous cell carcinoma (OSSC) represents $90 \%$ of oral malignancies (Silverman, 2001). Every year more than 300,000 new cases are being diagnosed with OSCC world wide.

The development of malignant neoplasms -including the oral cancer- is a complex process, and for their understanding animal models of carcinogenesis that accurately represent the cellular and molecular changes associated with initiation and progression of human oral cancer have been deployed (Rivera et al., 2011), from normal tissues to pathological conditions, which are then capable of being analyzed using histopathologic, genetic and biochemical techniques (Herzig et al., 2002).

One of the animal models of carcinogenesis most used is that by chemical induction with 4-nitroquinoline 1-oxide (4NQO) (Dayan et al., 1997; Rivera et al.). The 4NQO is a powerful carcinogen in several organs, and it can specifically induce tongue SCC when applied in low concentrations via drinking water (El-Rouby, 2011).

The aim of this review is to present the most used method to induce oral cancer, experimentally.

Carcinogenesis. Carcinogenesis is the process by which normal cells or tissues become transformed into cancer (Levy, 1963; Kumar et al., 2005). This implies a carcinogen, a substance which will transform normal to malignant cells (Levy et al., 1950). Carcinogens can be essentially divided into DNA-reactive genotoxic and nongenotoxic types on the basis of their mechanisms of action. They can cause initiated cells to develop into preneoplastic and neoplastic lesions by stimulating clonal proliferation (Miranda et al., 2011).

A large number of agents are capable of producing genetic damage and induce malignant transformation. These include chemical and physical carcinogens, oncogenic viruses and some other microorganisms (Kumar et al.; Jiang et al., 2007; Choi \& Myers, 2008).

In the process of carcinogenesis, cellular alterations at the molecular level are the first to occur, such as alterations in the genetic material which are not detectable by conventional histopathology. The accumulation of these molecular changes over time, causing individual cell changes that subsequently will be massive and may be detected histologically, and then when the number of altered cells is significant, it is possible to observe macroscopic changes in the affected areas.

Chemical carcinogenesis. Many carcinogenic chemicals have been identified that are involved in the development of various tumors. The induction of genetic alterations by chemical carcinogenesis involves 3 stages: initiation, promotion and progression.

* Department of Basic Biomedical Sciences, Faculty of Health Sciences, University of Talca, Talca, Chile.

** Master Program in Biomedical Sciences, mention in Oral Pathology, University of Talca, Talca, Chile. 
Initiation: Is the response to exposure of cells to sufficient doses of carcinogen (initiator), an initiated cell is altered, making it potentially capable of giving rise to a tumor. However, the initiation alone is not sufficient for tumor formation. The initiation produces permanent damage to the DNA (mutations), therefore it is irreversible and has memory (Kumar et al.).

Promotion: This phase is mediated by so-called promoters, agents that can induce tumors in initiated cells, but which by themselves are not tumorigenic and can act on the initiated cells several months after application of the initiator. In contrast to the effects of the initiators, the cellular changes resulting from the application promoters do not directly affect the DNA and are reversible. For example, they can increase proliferation of initiated cells, an effect that may contribute to the development of additional mutations (Kumar et al.). The promotion is reversible in the early stages if the promoter agent is eliminated (Stevens \& Lowe, 2001).

Progression: If it persists in cell proliferation, initiated cells acquire new genetic alterations in oncogenes, which result in deregulation of growth and, sometimes, in autonomous growth. The end point of this progression is the development of an invasive tumor (Stevens \& Lowe).

Although many agents are initiators or promoters, others behave as both, which defines them as a complete carcinogen (Stevens \& Lowe).

Experimental Oral Carcinogenesis. The main animal models of carcinogenesis using chemical agents, probably because the chemical constituents of tobacco and alcohol were quickly identified as possibly responsible for most human OSCC (Mognetti et al., 2006).

No animal model is perfectly applicable to any type of human cancer. However, there is consensus to use an animal model is an unavoidable step to understanding the processes and human diseases such as the process of carcinogenesis and the evaluation of therapeutic interventions. Experimental animal models that accurately represent the cellular and molecular changes associated with the initiation and progression of human cancer, are of crucial importance, although some are more suited for certain applications than others (Mognetti et al.).

Early attempts to induce malignant oral tumors were largely unsuccessful, as the oral mucosa is considerably more resistant to the actions of chemical carcinogens than skin (Eveson, 1981). This difference in susceptibility is explained by the presence of saliva in the oral cavity, which has a protective effect (Vered et al., 2010).
The first animal model of chemical induced OSCC was used in Syrian hamsters. These animals have a pocket on each cheek, whose anatomical feature allows easy access (MacDonald, 1981). The first successful chemical agent used was 9,10-dimethyl-1,2-benzanthracene (DMBA), either dissolved in acetone or benzene (Salley, 1954).

However, application of DMBA is laborious locally. Also acetone and benzene have local toxic effects. Additionally, Syrian hamster oral mucosa, despite having a stratified squamous epithelium, is very different from the human (MacDonald; Nauta et al., 1995).

Animal models have long been confined to chemically induced oral carcinomas, probably because the chemical components of tobacco and alcohol were quickly identified as responsible for most human OSCC (Mognetti et al.).

4NQO oral squamous cell carcinoma model. The medium term tongue carcinogenesis assay is a useful model for studying OSSC phase by phase. The animal model of chemical carcinogenesis induced locally or systemically by 4-nitroquinoline-1-oxide (4NQO) is considered the most representative model to study OSSC (Dayan et al.; Rivera et al.). This model is based on the multi-step process of carcinogenesis, which is characterized by initiation, promotion, and tumor progression (Fracalossi et al., 2011; Minicucci et al. 2011).

The 4NQO (Fig. 1) is a synthetic carcinogen derivative of a quinoline, soluble in water, sensitive to high temperature and light (Wilkey et al., 2009). Is used to study the various stages of oral carcinogenesis, because it is capable of inducing sequentially the phases of carcinogenesis (hyperplasia, dysplasia, severe dysplasia, carcinoma in situ and OSSC) (Wilkey et al.). The 4NQO is a powerful chemical carcinogen whose carcinogenic action is initiated by the enzymatic reduction of its nitro group (Nagao \& Sugimura, 1976; Kitano, 2000). The four-electron reduction product 4-hydroxyaminoquinoline 1-oxide (4HAQO) is believed to be the proximate carcinogenic metabolite of 4NQO. When metabolized to an electrophilic reactant, selyl-4HAQO, it reacts with DNA to form stable quinoline monoadducts such as 3-(deoxyadenosin-N6-yl)$4 \mathrm{AQO}$ and N4-(guanosin-7-yl-4AQO) which are considered responsible for its mutagenicity and genotoxicity (Tada \& Tada, 1975; Kohdab et al., 1991). 4Nitroquinoline 1-oxide (4NQO) elicits its carcinogenicity by producing DNA adducts after being metabolized to 4hydroxyaminoquinoline 1-oxide, which forms 8hydroxydeoxyguanosine $(8 \mathrm{OHdG})$ which is responsible for its oxidative damage (Arima, 2006). 
<smiles></smiles>

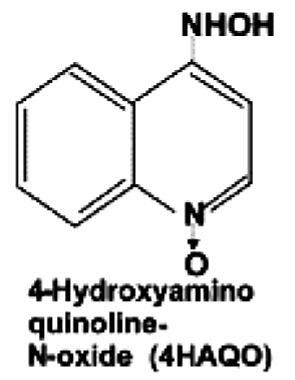<smiles></smiles><smiles>O=[N+]([O-])c1cc[n+]([O-])c2ccccc12</smiles>
4-Nitro anion radical<smiles>O=[N+]([O-])c1ccc2ccccc2[n+]1[O-]</smiles>

Nitroxide radical
4Nitrosoquinoline N-oxide

Fig. 1. Structures of $4 \mathrm{NQO}$ and its metabolites (Koontongkaew et al., 2000).

Depending upon the dose and duration of treatment, 4NQO induces a spectrum of dysplastic and neoplastic lesions in the oroesophageal epithelium, with morphological and molecular alterations that mimic those occurring in human oral epithelial preneoplastic and neoplastic lesions (Wilkey et al.).

The carcinogenic mechanism of action of $4 \mathrm{NQO}$ is through the generation of reactive oxygen species (ROS) and nitrogen

(RNS) such as superoxide radicals, hydrogen peroxide and nitric oxide, which induce intracellular oxidative stress (Nunoshiba \& Demple, 1993). ROS/RNS damage directly and indirectly to macromolecules, including the DNA, predominantly by binding of guanine residues, leading to adducts (Kanojia \& Vaidya, 2006).

The damage described is similar to those caused by other carcinogens present in the tobacco, which is an important risk factor for oral cancer. Also exposure to 4NQO produces molecular and cellular changes that lead to histopathological changes similar to those seen in human OSCC (Kanojia \& Vaidya).

Chronic administration of $4 \mathrm{NQO}$ in water simulates tongue carcinogenesis in rats, similar to its human homolog (Minicucci et al., 2009). The oral mucosa of tongue dorsum of mice has also been used to induce tumors massively, mainly in strains CBA, C57BL/6, BALB/C and others. There has been a $100 \%$ incidence of lesions in animals. Histopathological analysis indicated that these lesions were squamous dysplasias, papillomas and invasives OSSC (Tang et al., 2004). Figure 2 shows a well-differentiated carcinomas induced by $4 \mathrm{NQO}$.

The model of carcinogenesis in rat and mouse is more appropriate to study OSSC,
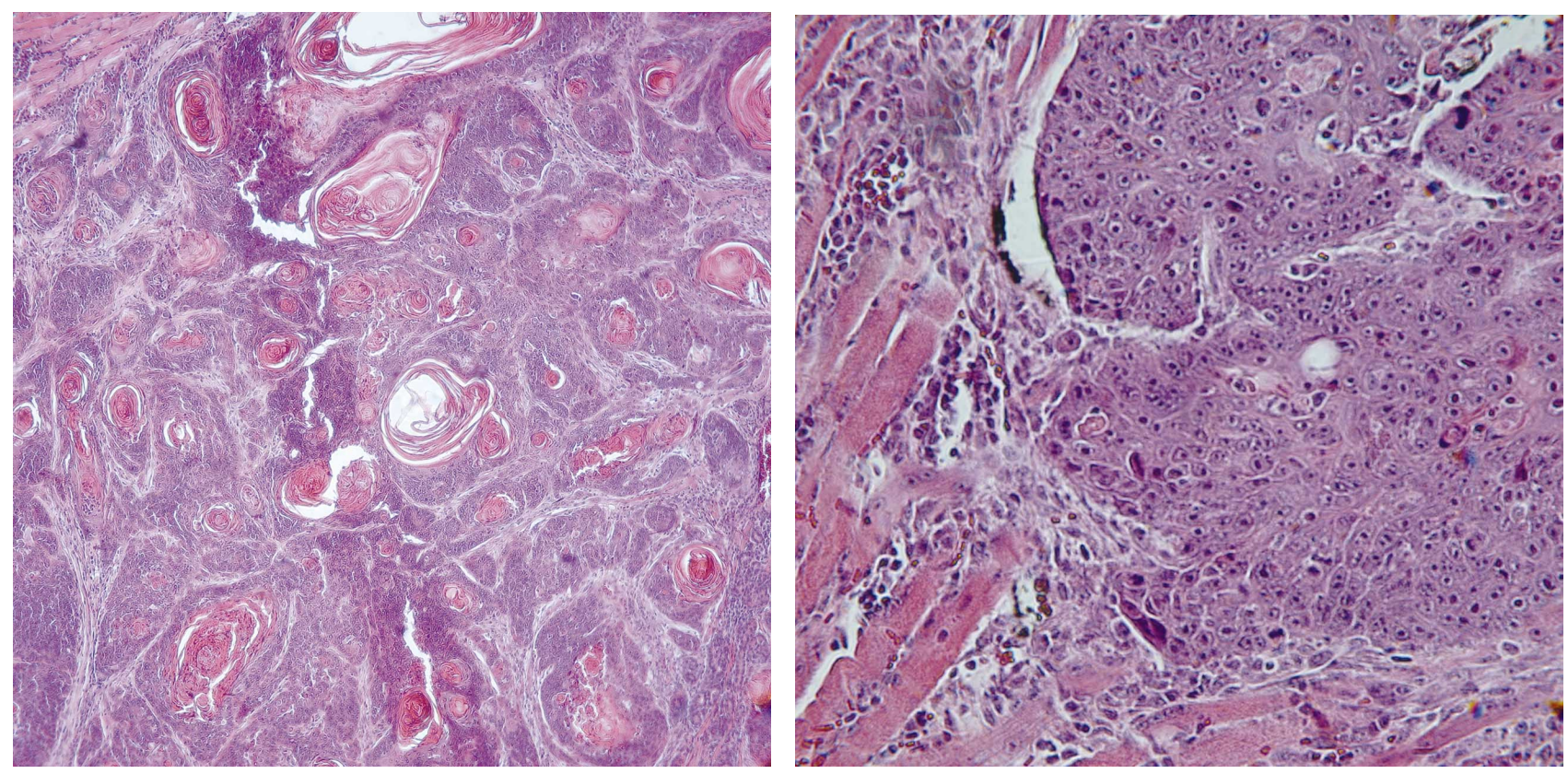

Fig. 2. Well-differentiated (A) and moderately differentiated (B) OSSC induced by 4NQO. 


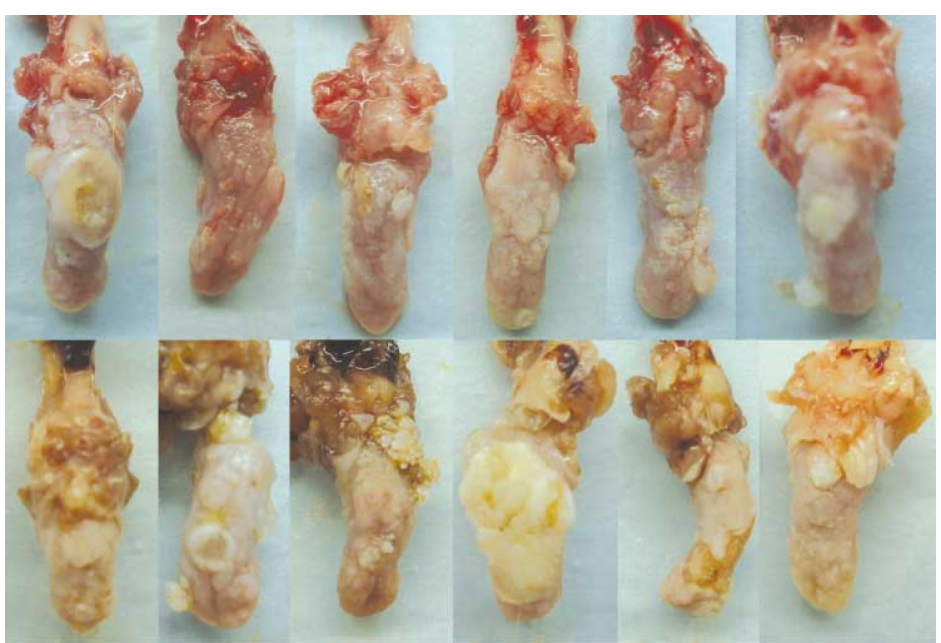

Fig. 3. Mice tongue lesions induced by 4NQO.

because the oral mucosa of these animals is similar to human oral mucosa, especially in palate and tongue (MacDonald; Nauta et al., 1996). Another advantage of this model is the possibility of chemical management in systemic, long-term and lower doses, reducing further adverse effects (Vered et al., 2005).

There is a lag time between the onset of molecular changes (not detectable with conventional light microscopy), the onset of histopathological changes (detectable) and the macroscopic and clinical appearance of lesions (MacDonald; Ribeiro et al., 2004; Vered et al.). Figure 3 shows macroscopic tongue lesions.

The histopathological changes in the tongue epithelium during carcinogenesis pass from mild to moderate and severe dysplasia before the onset of OSSC. The initiation, with irreversible cellular changes, occurring within 4 weeks of systemic administration of $4 \mathrm{NQO}$, through drinking water (Steidler \& Reade, 1986). The latency period between first histopathology manifestations and macroscopic lesions in this model is 8 weeks (Salley, 1954, Vered et al.).

Experimental protocols used vary extensively, however, concentrations of carcinogen used are similar (Steidler \& Reade; Nauta et al., 1996; Vered et al.).

In order to validate models of chemical carcinogenesis in animals have been developed for comparative studies in humans and animals OSSC, relative to the carcinogen activation markers, oxidative stress, cell proliferation, apoptosis, invasion, and angiogenesis. The results reveal aberrant expression of multiple molecules in the main signaling pathways in both OSSC (Nagini et al., 2009), establishing these models of study as an important tool for monitoring oral oncogenesis.

\section{DISCUSSION}

Animal models permit the development and testing of new approaches to disease prevention and treatment, identification of early diagnostic markers and novel therapeutic targets, and an understanding of the in vivo biology and genetics of tumor initiation, promotion, progression and metastasis.

The aim of chemical carcinogenesis model is to provide further understanding concerning the multi-step process of carcinogenesis in order to investigate hazard risk caused by environmental agents as well as to develop strategies for early diagnostic and/or cancer prevention (Miranda $e t$ al.).

The 4NQO can be administered orally in drinking water and therefore is easy to apply (Tang et al.). This model is effective because of a close similarity to human oral carcinogenesis at both histological as well as molecular level. Here, controlled conditions can be maintained with limited variations, which allow the reproducible isolation of all the stages of carcinogenesis and hence provide an excellent opportunity to intervene the neoplastic progression, as the premalignant stages are identifiable. Unfortunately, conditions often vary from study to study, such as the doses of $4 \mathrm{NQO}$ and species and strains used.

The two most frequent used experimental procedures for investigating therapies are in vitro cell lines and the nude mouse. The 4NQO model has several advantages and disadvantages over these laboratory experiments. Compared with the cell lines and the nude mouse model, the close similarity of the 4NQO model to the physiological process is a big benefit. The biggest drawback of the nude mouse model is the lack of an immunocompetent component. The clear disadvantage of the 4NQO model is that both the cell line and the bare mouse are less time consuming and that cell line experiments are less costly and most of the time readily available (Schoop et al., 2009).

Currently it has started to be used simultaneously 4-NQO (200 $\mu \mathrm{g} / \mathrm{mL})$ more and arecoline $(500 \mu \mathrm{g} / \mathrm{mL})$, in order to increase the incidence of malignant lesions (Chang et al., 2010). 
The 4NQO model is still the most used, however, transgenic models are very recent and very promising, considering that the genetics of animals is known, these models seek to standardize the model of oral carcinogenesis, an example of them, the K14-CreERtam/LSL-K-rasG12D/ +/p53flox/flox two-hit animal model system (Raimondi et al., 2009) that may represent a suitable platform for exploring the underlying molecular mechanism and genetic and epigenetic event determining the susceptibility to malignant progression of tumoral lesions arising from the distinct stratified epithelia of the oral cavity.

In conclusion, taking advantages and disadvantages in to account the 4NQO oral tumor model has clear benefits and seems suitable for therapeutic research applications, however we must remain alert to emerging models.

RIVERA, M. C. A. Carcinogenesis inducida por 4NQO: un modelo de carcinoma oral de células escamosas. Int. J. Morphol., 30(1):309$314,2012$.

RESUMEN: La carcinogénesis oral experimental inducida por el químico 4-nitroquinolina 1-óxido (4NQO) es uno de los métodos más frecuentes en el estudio del carcinoma de células escamosas de la cavidad oral (CCECO). La clara ventaja del modelo radica en el gran parecido al proceso fisiológico de la neoplasia maligna. El modelo tiene beneficios claros y es adecuado para las aplicaciones de la investigación terapéutica.

PALABRAS CLAVE: 4NQO; Carcinogénesis experimental; Carcinoma oral de células escamosas; Lengua.

\section{REFERENCES}

Arima, Y.; Nishigori, C.; Takeuchi, T.; Oka, S.; Morimoto, K.; Utani, A. \& Miyachi, Y. 4-Nitroquinoline-1-oxide forms 8hydroxydeoxyguanosine in human fibroblasts through reactive oxygen species. Toxicol. Sci, 91:382-92, 2006.

Chang, N. W.; Pei, R. J.; Tseng, H. C.; Yeh, K. T.; Chan, H. C.; Lee, M. R.; Lin, C.; Hsieh, W. T.; Kao, M. C.; Tsai, M. H. \& Lin, C. F. Co-treating with arecoline and 4-nitroquinoline 1-oxide to establish a mouse model mimicking oral tumorigenesis. Chem. Biol. Interact., 183:231-37, 2010.

Choi, S. \& Myers, J. N. Molecular pathogenesis of oral squamous cell carcinoma: implications for therapy. J. Dent. Res., 87:1432, 2008.

Dayan, D.; Kaplan, I.; Russack, S. \& Bodner, L. Dysplastic changes of the palate and tongue mucosa induced by topically applied 4 nitro-quinoline- $N$-oxide $(4 N Q O)$ in desalivated rats. In: Harris, M.; Johnson, N. \& Varma, A. K. (eds.). Oral oncology. Proceedings of the 5th International Congress on Oral Cancer. London, MacMillan India Ltd., 1997. pp.514-7.

El-Rouby, D. H. Histological and immunohistochemical evaluation of the chemopreventive role of lycopene in tongue carcinogenesis induced by 4-nitroquinoline-1-oxide. Arch. Oral Biol., 56:664-71, 2011.

Eveson, J. W. Animal models of intra-oral chemical carcinogenesis: a review. J. Oral Pathol., 10:129-46, 1981.

Fracalossi, A. C.; Comparini, L.; Funabashi, K.; Godoy, C.; Iwamura, E. S.; Nascimento, F. D.; Nader, H. B.; Oshima, C. T. \& Ribeiro, D. A. Ras gene mutation is not related to tumour invasion during rat tongue carcinogenesis induced by 4-nitroquinoline 1-oxide. J. Oral Pathol. Med., 40:325-33, 2011.
Herzig, M. \& Christofori, G. Recent advances in cancer research: mouse models of tumorigenesis. Biochim. Biophys. Acta, 1602:97-113, 2002.

Jiang, C.; Ye, D.; Qiu, W.; Zhang, X.; Zhang, Z.; He, D.; Zhang, P. \& Chen, W. Response of lymphocyte subsets and cytokines to Shenyang prescription in Sprague-Dawley rats with tongue squamous cell carcinomas induced by 4 NQO. BMC Cancer, 7:40, 2007

Kanojia, D. \& Vaidya, M. M. 4-Nitroquinoline-1-oxide induced experimental oral carcinogenesis. Oral Oncol., 42:655-67, 2006.

Kohda, K.; Kawazoe, Y.; Minoura, Y. \& Tada, M. Separation and identification of N4-(guanosine-7-yl)-4-aminoquinoline-1-oxide, a novel nucleic acid adduct of carcinogen 4-nitroquinoline 1-oxide. Carcinogenesis, 12:1523-5, 1991.

Kitano, M. Host genes controlling the susceptibility and resistance to squamous cell carcinoma of the tongue in a rat model. Pathol. Int., 50:353-62, 2000 .

Koontongkaew, S.; Chareonkitkajorn, L.; Chanvitan, A.; Leelakriangsak, M. \& Amornphimoltham, P. Alterations of p53, $\mathrm{pRb}$, cyclin $\mathrm{D}(1)$ and cdk4 in human oral and pharyngeal squamous cell carcinomas. Oral Oncol., 36:334-9, 2000.

Kumar, V.; Abbas, A. \& Fausto, N. Robbins y Cotran. Patología Estructural y Funcional. 7 ed. Madrid, Elsevier, 2005. pp.273346.

Levy, B. M.; Gorlin, R. \& Gottsegen, R. A histologic study of the reaction of skin and mucous membrane to a single application of 9,10 dimethyl-1,2,benzanthracene. J. Dent. Res., 29:678-9, 1950.

Levy, B. M. Experimental oral carcinogenesis. J. Dent. Res., 42:3217, 1963. 
MacDonald, D. G. Comparison of epithelial dysplasia in hamster cheek pouch carcinogenesis and human oral mucosa. J. Oral Pathol., 10:186-91, 1981.

Minicucci, E.; da Silva, G.; Ribeiro, D. \& Favero, D. No mutations found in exon 2 of gene p16CDKN2A during rat tongue carcinogenesis induced by 4-nitroquinoline-1-oxide. J. Mol. Histol., 40:71-6, 2009.

Minicucci, E. M.; Ribeiro, D. A.; da Silva, G. N.; Pardini, M. I.; Montovani, J. C. \& Salvadori, D. M. The role of the TP53 gene during rat tongue carcinogenesis induced by 4nitroquinoline 1-oxide. Exp. Toxicol. Pathol., 63:483-9, 2011.

Miranda, S. R.; Noguti, J.; Carvalho, J. G.; Oshima, C. T. \& Ribeiro, D. A. Oxidative DNA damage is a preliminary step during rat tongue carcinogenesis induced by 4-nitroquinoline 1-oxide. $J$. Mol. Histol., 42:181-6, 2011.

Mognetti, B.; Di Carlo, F. \& Berta, G. N. Animal models in oral cancer research. Oral Oncol., 42:448-60, 2006.

Nagao, M. \& Sugimura, T. Molecular biology of the carcinogen, 4-nitroquinoline 1-oxide. Adv. Cancer Res., 23:131-69, 1976.

Nagini, S.; Letchoumya, P. V.; Thangavelu, A. \& Ramachandran, C. Of humans and hamsters: A comparative evaluation of carcinogen activation, DNA damage, cell proliferation, apoptosis, invasion, and angiogenesis in oral cancer patients and hamster buccal pouch carcinomas. Oral Oncol., 45:e317, 2009 .

Nauta, J. M.; Roodenburg, J. L.; Nikkels, P. G.; Witjes, M. J. \& Vermey, A. Comparison of epithelial dysplasia: the 4NQO rat palate model and human oral mucosa. Int. J. Oral Maxillofac. Surg., 24:53-8, 1995.

Nauta, J. M.; Roodenburg, J. L.; Nikkels, P. G.; Witjes, M. J. \& Vermey A. Epithelial dysplasia and squamous cell carcinoma of wistar rat palatal mucosa: 4NQO model. Head Neck, 18:4419, 1996

Nunoshiba, T. \& Demple, B. Potent intracellular oxidative stress exerted by the carcinogen 4-nitroquinoline-N-oxide. Cancer Res., 53:3250-2, 1993.

Parkin, D. M.; Bray, F.; Ferlay, J. \& Pisani P. Estimating the world cancer burden: Globocan 2000. Int. J. Cancer, 94:153-6, 2001.

Raimondi, A. R.; Molinolo, A. \& Gutkind, J. S. Rapamycin Prevents Early Onset of Tumorigenesis in an Oral-Specific K-ras and p53 Two-Hit Carcinogenesis Model. Cancer Res., 69:415966, 2009.

Ribeiro, D. A.; Fávero Salvadori, D. M.; da Silva, R. N.; Ribeiro Darros, B. \& Alencar Marques, M. E. Genomic instability in non-neoplastic oral mucosa cells can predict risk during 4nitroquinoline 1-oxide-induced rat tongue carcinogenesis. Oral Oncol., 40:910-5, 2004.
Rivera, C. A.; Droguett, D. A.; Kemmerling, U. \& Venegas B. A. Chronic Restraint Stress in Oral Squamous Cell Carcinoma. J. Dent. Res., 90:799-803, 2011.

Salley, J. J. Experimental carcinogenesis in the cheek pouch of the Syrian hamster. J. Dent. Res., 33:253-62, 1954.

Silverman, S. Jr. Demographics and occurrence of oral and oropharyngeal cancers. The outcomes, the trends, the challenge. J. Am. Dent. Assoc., 132:7S-11S, 2001.

Schoop, R. A.; Noteborn, M. H. \& Baatenburg de Jong, R. J. A mouse model for oral squamous cell carcinoma. J. Mol. Histol., 40:177-81, 2009.

Steidler, N. E. \& Reade, P. C. Initiation and promotion of experimental oral mucosal carcinogenesis in mice. J. Oral Pathol., 15:43-7, 1986.

Stevens, A. \& Lowe, J. Anatomía Patológica. 2 ed. Barcelona, Elsevier, 2001. pp.97-9.

Tada, M. \& Tada, M. Seryl-tRNA synthetase and activation of the carcinogen 4-nitroquinoline-1-oxide. Nature, 255:510-2, 1975.

Tang, X. H.; Knudsen, B.; Bemis, D.; Tickoo, S. \& Gudas, L. J. Oral cavity and esophageal carcinogenesis modeled in carcinogen-treated mice. Clin. Cancer Res., 10:301-13, 2004.

Vered, M.; Yarom, N. \& Dayan, D. 4NQO oral carcinogenesis: animal models, molecular markers and future expectations. Oral Oncol., 41:337-9, 2005.

Vered, M.; Grinstein-Koren, O; Reiter, S; Allon, I. \& Dayan, D. The effect of desalivation on the malignant transformation of the tongue epithelium and associated stromal myofibroblasts in a rat 4-nitroquinoline 1-oxide-induced carcinogenesis model. Int. J. Exp. Pathol., 91:314-23, 2010.

Wilkey, J. F.; Buchberger, G.; Saucier, K.; Patel, S. M.; Eisenberg, E.; Nakagawa, H.; Michaylira, C. Z.; Rustgi, A. K. \& Mallya, S. M. Cyclin D1 overexpression increases susceptibility to 4nitroquinoline-1-oxide-induced dysplasia and neoplasia in murine squamous oral epithelium. Mol. Carcinog., 48:853-61, 2009.

Correspondence to:

César Andrés Rivera Martínez

Cirujano Dentista

Universidad de Talca

Edificio Departamento de Ciencias Básicas Biomédicas

Avenida Lircay s/n Oficina $N^{\circ} 1$, Talca

CHILE

Email: contacto@cesarrivera.cl

Received: 18-08-2011

Accepted: 02-11-2011 